\title{
Adiponectin in psoriasis and its comorbidities: a review
}

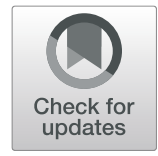

\author{
Bai Ruiyang ${ }^{1+}$, Adriana Panayi ${ }^{2}$, Wu Ruifang ${ }^{1}$, Zhang Peng ${ }^{1 *}$ and Fu Siqi ${ }^{1 *+}$
}

\begin{abstract}
Psoriasis is a chronic, immune-mediated inflammatory skin disease characterized by abnormal T cell activation and excessive proliferation of keratinocytes. In addition to skin manifestations, psoriasis has been associated with multiple metabolic comorbidities, such as obesity, insulin resistance, and diabetes. An increasing amount of evidence has highlighted the core role of adipokines in adipose tissue and the immune system. This review focus on the role of adiponectin in the pathophysiology of psoriasis and its comorbidities, highlighting the future research avenues.
\end{abstract}

Keywords: Adiponectin, Comorbidity, Immunity, Psoriasis, T lymphocytes

\section{Introduction}

Psoriasis is a chronic skin inflammation involving hyperkeratosis and parakeratosis. It usually manifests as welldefined, raised, red plaques covered by silvery scales $[1,2]$ (Table 1). In the latest global epidemiological survey, the prevalence of psoriasis varied from $0.14 \%$ in East Asia to $1.99 \%$ in Australasia. The prevalence of psoriasis was also high in Europe and America [7]. The prevalence of psoriasis in Europe ranges from 0.6 to $6.5 \%$ and $3.15 \%$ in the US [8]. In China, the prevalence of psoriasis ranges from 0.44 to $0.54 \%$, with $97 \%$ of patients having psoriasis vulgaris and $28 \%$ of patients reporting a family history of psoriasis [9] (Table 2). The relationship between psoriasis incidence and age appears to be relatively linear [12]. Psoriasis, mediated by $\mathrm{T}$ cells and dendritic cells, is closely related to the immune system and various clinical manifestations represent the activation of different components of the immune system. The adaptive immune system is mainly involved in chronic plaque psoriasis, while innate immune and autoinflammatory reactions play key roles in generalized pustular psoriasis [16]. Psoriasis vulgaris is considered

\footnotetext{
* Correspondence: zhangpeng@csu.edu.cn; fusiqi@csu.edu.cn

${ }^{\dagger}$ Bai Ruiyang and Fu Siqi are co-first authors.

${ }^{1}$ Department of Dermatology, The Second Xiangya Hospital, Central South University, Changsha 410011, Hunan, China

Full list of author information is available at the end of the article
}

one of the easiest human diseases to study [17]. Patients with psoriasis have a higher incidence of severe infections than those without psoriasis [18]. Furthermore, it has been shown that psoriasis itself may affect other organs [19]. For example, psoriasis is an important predictor of advanced liver fibrosis, which is not linked to age, sex, body mass index (BMI), hypertension or diabetes [20].

Adipose tissue participates in many physiological and metabolic processes in the body and acts as an energy reserve and an endocrine organ. Although fat cells are the main component of adipose tissues, they also include immune cells (such as $\mathrm{T}$ lymphocytes and macrophages) [21]. Previous studies have reported that adipose tissue has important immune functions and may be a major source of pro-inflammatory mediators, which promote the development of chronic inflammation, insulin resistance and atherosclerosis, all of which are associated with metabolic abnormalities [22]. The concept of 'adipokine' was first introduced when leptin was found in white fat [23]. By producing adipokines, especially adiponectin, adipose tissue is involved in many metabolic processes, including energy storage and temperature regulation. Adiponectin can also act on monocytes by regulating the polarization and proliferation of macrophages, thereby actively participating in immune responses and reducing 
Table 1 The feature of different types of psoriasis [3-6]

\begin{tabular}{|c|c|}
\hline Types of Psoriasis & Feature \\
\hline Plaque psoriasis & $\begin{array}{l}\text { Sharply circumscribed, round-oval, or nummular (coin-sized) plaques. The lesions may initially begin as erythematous macules } \\
\text { (flat and } 1 \mathrm{~cm} \text { ) or papules, extend peripherally, and coalesce to form plaques of one to several centimeters in diameter. A white } \\
\text { blanching ring, known as Woronoff's ring, may be observed in the skin surrounding a psoriatic plaque. }\end{array}$ \\
\hline Guttate psoriasis & $\begin{array}{l}\text { Acute onset of a myriad of small, } 2-10 \mathrm{~mm} \text { diameter lesions of psoriasis. These are usually distributed in a centripetal fashion, it } \\
\text { can also involve the head and limbs. Classically, it occurs shortly after an acute } \beta \text {-haemolytic streptococcal infection of the phar- } \\
\text { ynx or tonsils and can be the presenting episode of psoriasis in children or adults occasionally. }\end{array}$ \\
\hline Pustular psoriasis & Multiple tender sterile pustules with an underlying, blotchy, erythematous base. The patient may be pyrexial. \\
\hline $\begin{array}{l}\text { Erythrodermic } \\
\text { psoriasis }\end{array}$ & $\begin{array}{l}\text { Generalized erythema involving the majority of the body surface area. It may be a manifestation of unstable psoriasis } \\
\text { precipitated by infection, tar, drugs, or withdrawal of corticosteroids. }\end{array}$ \\
\hline
\end{tabular}

T-cell reactivity and B-cell lymphocyte production [24]. Members of the C1q/TNF-related protein (CTRP) family, including adiponectin, play roles in metabolism and immunity [25]. A recent study suggested that adiponectin may also be a lipid carrier. Adiponectin and other CTRPs selectively bind to several anionic phospholipids and sphingolipids via the $\mathrm{C} 1 \mathrm{q}$ domain in an oligomerization-dependent fashion, functioning as lipid opsonins [26]. AdipoR1 and AdipoR2 were identified as receptors for adiponectin. They are ubiquitously expressed, but AdipoR1 is more highly expressed in skeletal muscle, while AdipoR2 is more restricted to the liver [27]. Once bound to its receptors, AdipoR1 and R2, adiponectin initiates a series of tissue-dependent signal transduction events, including phosphorylation of adenosine monophosphate protein kinase (AMPK) and p38 mitogen-activated protein kinase (p38 MAPK), and it increases peroxisome proliferator-activated receptor alpha (PPAR $\alpha)$ ligand activity, thereby reducing inflammation in various cell types [28]. For example, by inhibiting the nuclear factor $\kappa B(N F-\kappa B)$ signalling pathway, adiponectin has an anti-inflammatory effect [29]. In view of the structural similarities between adiponectin and the CTRP proteins, these receptors may also respond to other CTRP family members [30]. Adiponectin may form heterotrimers with CTRP2 and CTRP9, but these trimers can only be generated when all three proteins are co-expressed in the same cell [31].
Therefore, whether adiponectin plays a key role in psoriasis and the underlying mechanism should be investigated. This review discusses the relationship between adiponectin and psoriasis, including the role of adiponectin in comorbidities, and the potential role of adiponectin in preventing or slowing the progression of psoriasis and its related comorbidities.

\section{Adiponectin and psoriasis}

\section{Serum adiponectin and psoriasis}

Adiponectin is a $30 \mathrm{kDa}$ monomeric glycoprotein comprised of an N-terminal signal sequence, a nonhomologous or hypervariable region, a collagenous domain containing 22 collagen repeats, and a C-terminal C1qlike globular domain [28, 32]. Previous studies have suggested that adiponectin may be involved in the pathogenesis of psoriasis [33, 34]. Adiponectin plays an antiinflammatory role in keratinocytes and inhibits the production and activity of pro-inflammatory cytokines, including the interleukin cytokines IL-2, IL-6, IL-8, IL-17 and IL-22; tumour necrosis factor- $\alpha$ (TNF- $\alpha$ ); and interferon- $\gamma($ IFN- $\gamma)$ and IFN-g, while increasing the secretion of anti-inflammatory cytokines such as IL-10 [35-37]. In T lymphocytes, it was previously found that non-recombinant adiponectin inhibited the production of IL-17, IL-22, TNF- $\alpha$ and IFN-g in Hut102 cells, possibly through AdipoR1, and the expression of

Table 2 The incidence of psoriasis in all ages in different countries

\begin{tabular}{llll}
\hline Study & Country & Study period & Incidence rate per 100,000 person years (95\% Cl) \\
\hline Bell et al. (1991) [10] & USA & $1980-1983$ & $59.9(49.5 \text { to } 70.3)^{\mathrm{a}, \mathrm{b}}$ \\
Donker et al. (1998) [7] & Netherlands & 1995 & $120.0(70.0$ to 190.0.0 \\
Jacob et al. (2016) [11] & Germany & $2007-2010$ & $521.1^{\mathrm{a}}$ \\
Egeberg et al. (2017) [12] & Denmark & 2012 & $151.2(148.0 \text { to } 154.5)^{\mathrm{a}}$ \\
Springate et al. (2017) [13] & UK & 2013 & $129.0(126.0$ to 133.0) \\
Kubanova et al. (2017) [14] & Russia & 2016 & $65.0^{\mathrm{a}}$ \\
Schonmann et al. (2019) [15] & Israel & 2017 & $276(270$ to 281) \\
\hline
\end{tabular}

avalue reported from the study

${ }^{\mathrm{b}}$ Age or sex adjusted 
adiponectin R1 in psoriatic epidermis was decreased [38]. Most studies have shown lower adiponectin levels in psoriasis patients than in healthy controls [39-41]. In experiments with psoriasis patients and control groups, the reduction of adiponectin and IL-10 was the predominant feature, followed by changes in IL-2, IL-12 and IL17 [42]. Patients with psoriasis have lower plasma adiponectin levels, which may worsen the severity of their skin lesions [43]. Previous documents from 10 years ago revealed that plasma $\mathrm{C}$-reactive protein (CRP) levels are negatively correlated with plasma adiponectin levels, and a significant negative correlation between CRP and adiponectin mRNA levels was also observed in human adipose tissue $[44,45]$. However, in subsequent research, adiponectin serum levels were also positively correlated with the sedimentation rate (SR) and CRP levels, which was somewhat puzzling. Previously, the importance of this relationship in the course of psoriasis was unclear, but now it has been demonstrated that plasma adiponectin decreases and CRP increases as metabolic diseases progress $[44,46,47]$. Therefore, the reduction in adiponectin levels is closely related to the occurrence of psoriasis. As an inflammatory factor, CRP participates with various cytokines in the immune response and may play an important role in promoting the development of psoriasis.

Previous research on adiponectin focused on TNF- $\alpha$ and IL-6, which inhibit anti-inflammatory defences, particularly adiponectin levels [45]. Data from human and rodent in vivo studies have shown that adiponectin levels are negatively correlated with TNF- $\alpha$ and IL-6 [48-50]. Increased levels of pro-inflammatory cytokines, especially IL-6, in patients with psoriasis may be one of the causes of the decline in adiponectin levels in subcutaneous and visceral adipose tissue $[51,52]$. Adiponectin can inhibit TNF- $\alpha$ [53], which can also be negatively regulated by TNF- $\alpha$ in psoriatic patients [54]. Anti-TNF therapy has also been found to decrease IL-6 levels in patients with psoriasis [55]. In addition, upregulation of anti-inflammatory cytokines helps restore the balance between Th (helper T cell) 1, Th17 and Th2 responses in patients with psoriasis [56]. In an AMPK-dependent manner, adiponectin inhibits Th0 cell differentiation into Th1 and Th17 cells [57]. Among its anti-inflammatory effects is inhibition of IL-17A production [58]. Adiponectin-deficient mice suffer from severe psoriasislike skin inflammation and increased infiltration of IL-17 secreting skin $\mathrm{V}_{\gamma} 4 \gamma \delta$ - $\mathrm{T}$ cells, particularly upregulation of the Th17-related cytokines IL-17A, IL-17F and IL-22 [58]. Moreover, adiponectin also inhibits the synthesis and secretion of cytokine IL-17 by human CD4 (+)/CD8 (+) T cells [59] (Fig. 1). Consequently, adiponectin plays a key role in regulating psoriasis by directly inhibiting the secretion of IL-17 by $\mathrm{T}$ cells, which suggests new approaches to the study of psoriasis. Similar to adipocytes, sebaceous cells have also been found to differentially express and secrete adipokines. Adiponectin is expressed in human sebaceous glands (SGs), affecting the homeostasis of the dermis and promoting inflammation. Its relationship with systemic inflammation such as psoriasis is an interesting research pathway [68].

Subgroup and meta-regression analyses have found no significant correlation in terms of age, sex, psoriasis area and severity index (PASI) or study quality score with the expression level of adiponectin in psoriasis $[39,46]$. This contrasts with previous findings that adiponectin levels are negatively correlated with PASI $[54,58,69]$. Despite the fact that most reports find the former [33, 50], there are indications that although the PASI score is negatively correlated with adiponectin levels, the correlation is very weak and therefore not clinically relevant [70]. Regarding the contradiction in the correlation between serum adiponectin and PASI, recent articles have shown that adiponectin is significantly reduced in the plasma of patients with mild $(\mathrm{PASI}<10)$ or moderate $(\mathrm{PASI}<20)$ forms of psoriasis, but it does not differ from controls in patients with severe psoriasis (PASI $>20$ ) [46]. There are also articles suggesting that there is no correlation between adiponectin and PASI scores. This may be because most of the study subjects were patients with mild psoriasis, so a low PASI score indicates low disease activity with low TNF-a levels [71], meaning that the degree of correlation could be related to the patient sample selection. For the exact relationship between adiponectin and PASI, a single correlation cannot be used to discuss the overall relationship.

\section{Local adiponectin and psoriasis}

There is increasing evidence that adipose tissue is locally involved in the pathophysiology of psoriasis and that dermal adipocytes participate in the steady-state temperature regulation of the skin [72-74]. In psoriasis, many different microorganisms play a pathogenic role, including Staphylococcus aureus [75]. Recent observations have found that after $S$. aureus infects the skin of mice, preadipocytes proliferate rapidly, and mice with impaired adipogenesis have a reduced protective effect against the infection, indicating that dermal adipocytes are also involved in skin protection against infection [76]. At the same time, skin without lesions in psoriasis demonstrates the same upregulation of cathelicidin expression after barrier disruption as the original psoriatic lesions, indicating that this response is local, not systemic [77].

Skin inflammation in patients with psoriasis is restricted to psoriatic plaques. This observation supports a primary local modification of the superficial layer of the subcutaneous white adipose tissue (sWAT) underneath 


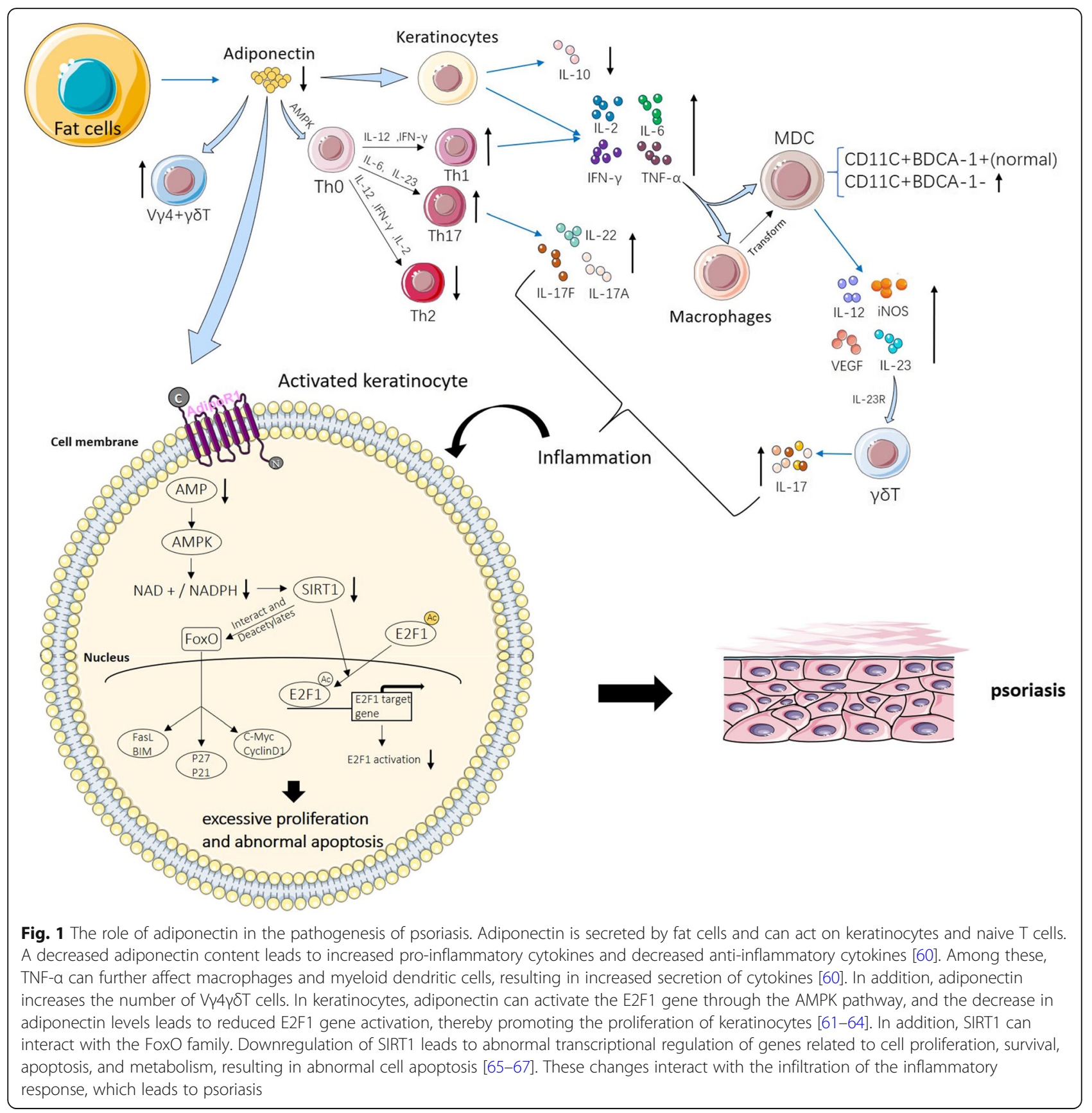

the psoriatic plaques $[72,74]$. It has been found that the local concentrations of adiponectin and TNF- $\alpha$ in sWAT were not significantly different between the control group and the psoriasis and/or metabolic syndrome group [73]. Another study found that the local adiponectin levels in the healthy skin and skin lesions of psoriasis patients were substantially lower than those in the control group [58]. The results of the former study may have been caused by the patients discontinuing hormone therapy before biopsy. This may have changed the local concentration of adipokines in the sWAT during the biopsy [73].

Ultrasound elastography can identify the involvement of subcutaneous adipose tissue in patients with plaque psoriasis and it can be used as an effective method to evaluate the early treatment response of patients with plaque psoriasis. The average strain ratio of the psoriasis lesion area was significantly higher than that of the nonlesion area [78]. Effective psoriasis treatment can greatly reduce the WAT hardness under the plaque, making it 
equivalent to the normal value of non-lesion skin, and this is related to an improvement in skin condition [79]. Therefore, the pathophysiology of psoriasis is not limited to the epidermis but should also include the spatially restricted tissue composite containing the skin and the adjacent WAT. Compared with changes in serum adiponectin levels, whether changes in local adiponectin levels have a greater impact on psoriasis is of interest.

\section{Adiponectin and psoriasis comorbidities Adiponectin and obesity}

Psoriasis has been linked to obesity [80], especially abdominal obesity [81]. Obesity can also exacerbate existing psoriasis [82]. Abdominal obesity has been associated with a substantially low adiponectin level, demonstrated by a negative correlation between adiponectin level and waist circumference [71]. Obesity and psoriasis have a common pathogenic mechanism involving the fat cells critical for the synthesis of the proinflammatory cytokines IL- 6 and TNF- $\alpha$ [42]. Because of the presence of these cytokines, macrophages infiltrate into the adipose tissue, and mature macrophages stimulate the secretion of cytokines, resulting in localized primary inflammation. Cytokines also trigger the production of inflammation-related proteins, leading to the low-level systemic inflammation observed in obesity $[83,84]$. Obesity through pro-inflammatory pathways can induce the development of psoriasis and is a key factor in the progression of psoriasis in children [85]. Adiponectin levels decrease in obese patients $[37,86]$. The diet-induced obesity model (DIO) has decreased adiponectin levels, while a high-fat diet (HFD) increases the frequency of $\mathrm{T}$ cells that are positive for IFN- $\gamma$ and IL17 [57, 87]. In early studies, meta- analyses showed no clear association between adiponectin levels and BMI [33], but later studies have shown that adiponectin levels are inversely proportional to BMI and low-density lipoprotein (LDL) and cholesterol levels [88-90]. In overweight or obese psoriasis patients, adiponectin levels have been observed to be significantly lower than in normal-weight psoriasis patients, but no hypoadiponectinemia was found [50, 70]. The high-molecular-weight adiponectin/total adiponectin ratio is decreased in patients with psoriasis [91]. Moreover, obesity is a predictor of poor treatment outcomes [92]. The use of methotrexate and anti-TNF treatment reduces the risk of comorbidities and is conducive to improvement of psoriasis [82], but anti-TNF-a antibody therapy is associated with an increase in adiposity. During anti-TNF-a treatment, the BMI of patients with psoriasis increase significantly [93]. The BMI increased by three points in patients treated with infliximab for 3 years [94]. Because of this adverse effect, some patients choose to terminate the treatment. Moreover, some studies claim to find no correlation between BMI and the severity of psoriasis $[50,70]$.

\section{Adiponectin and cardiovascular disease}

There is biological plausibility for the link between psoriasis inflammation and cardiovascular disease because there is a common pathogenic mechanism. $\mathrm{T}$ cells have a welldefined contributory role to psoriasis. In atherosclerosis, naive $\mathrm{T}$ cells are known to play a pro-inflammatory role; once they migrate across the arterial lumen into the intima, they exhibit the characteristics of pro-inflammatory Th1 and Th17 cells $[95,96]$. In addition, dyslipidaemia and atherosclerosis have been linked to reduced adiponectin levels [45, 97]. Adiponectin acts on endothelial cells, increasing local nitric oxide production, protecting endothelial function, and inhibiting plaque and thrombosis [98]. Nitric oxide (NO) derived from adipocytes can activate calcium-mediated potassium channel opening in vascular smooth muscle cells (VSMCs) and induce vasodilation [99]. Adiponectin also interacts with forkhead box $\mathrm{O} 1$ (FoxO1) to resist oxidative stress and inflammatory arterial damage by forming the FoxO1-C/enhancerbinding protein alpha transcriptional complex $[100,101]$ and inhibiting TNF- $\alpha$-induced activation and the adhesion of monocytes to endothelial cells. Therefore, adiponectin may be significant in the prevention of atherosclerosis [102]. In terms of lifestyle, consumption of a HFD can cause an imbalance in the production of biomolecules around perivascular adipose tissue (PVAT), including increased TNF- $\alpha$ and IL- 6 and decreased adiponectin levels, which in turn can lead to vascular dysfunction [103]. In high-risk populations with advanced atherosclerosis or other chronic inflammatory diseases, elevated adiponectin levels may be part of a compensatory mechanism that limits further endothelial damage $[104,105]$. Patients with psoriasis receiving anti-TNF immune targeting and fumaric acid ester (FAE) have been shown to have a better prognosis [106, 107]. Not only does the PASI score improve, but adiponectin also increases, while highsensitivity CRP decreases slightly [108]. Olive leaf extract can also significantly improve the expression of key adipogenic genes (such as PPAR, adiponectin and leptin receptors) in HFD-induced adipose tissue and can reverse the endothelial dysfunction observed in the aortic ring of obese mice [109]. This may be a promising new therapy for psoriasis and comorbidities. The role of adiponectin in conditions such as atherosclerosis and obesity has limited its use as a prognostic indicator for cardiovascular disease (CVD) in the general population [110-112] and as a biomarker for psoriasis patients with CVD [113].

\section{Adiponectin and diabetes}

Psoriasis is associated with type 2 diabetes (T2D) [81]. Although diabetes is the least common component of 
metabolic syndrome, it is the most common cause of complications of advanced psoriasis [114]. Adipokines such as fetuin A and pro-inflammatory cytokines promote insulin resistance and disorders of energy and lipid metabolism [115]. In psoriasis, in addition to reducing adiponectin levels, fetuin A, may also contribute to excessive keratinocyte proliferation. Whether this is dependent on or independent of insulin desensitisation, it can further enhance metabolic syndrome and skin inflammation in psoriasis $[116,117]$. Adiponectin levels in patients with psoriasis without diabetes are significantly higher than those of patients with progressive diabetes [70]. Substantially downregulated expression of adiponectin and its receptors in adipose tissues were also linked with diabetic dyslipidaemic conditions [47]. Experiments have shown that serum insulin levels and the insulin resistance index are positively correlated with the severity of psoriasis [118]. Adiponectin is also a significant regulator of the metabolic environment and energy balance, enhancing insulin sensitivity and reducing liver glycogen production [82, 119]. Therefore, lipid metabolism can be enhanced by increasing lipid clearance from the plasma, which can help improve blood glucose control [120]. In terms of treatment, anti-TNF immunetargeted therapy, such as adalimumab, and skin-directed therapy, such as ultraviolet $\mathrm{B}$ phototherapy, can reduce skin inflammation in patients with psoriasis, but adiponectin-induced glucose levels or insulin resistance do not change [55]. Systemic treatment with methotrexate results in a significant decrease in insulin levels and the insulin resistance index [118]. Pitavastatin has been shown to consistently increase plasma adiponectin, and it does not lead to new-onset or statin-induced diabetes $[121,122]$. Perhaps statin therapy should be considered earlier in psoriatic patients with low adiponectin values [71].

\section{Adiponectin and other comorbidities Non-alcoholic fatty liver disease}

A correlation between non-alcoholic fatty liver disease (NAFLD) and psoriasis has been reported. Specifically, psoriasis patients have a higher probability of NAFLD [123], while the presence of NAFLD itself may exacerbate the severity of psoriatic skin lesions [124]. NAFLD is often seen in patients with early-onset psoriasis (74.2\%), a diagnosis particularly common in patients younger than 40 years of age [114]. Adipokines play an important role in the pathogenesis of NAFLD, particularly adiponectin $[115,125]$. Patients with psoriasis complicated by NAFLD have been shown to have lower adiponectin levels than patients with psoriasis alone $[126,127]$. An in vivo study has shown that adiponectin deficiency not only increase the expression of NF- $\mathrm{kB}$, but also promote the accumulation of lipid droplets and increase the production of reactive oxygen species (ROS), thereby aggravating liver damage and steatosis in an HFD-induced NAFLD mouse model [128]. In patients with psoriasis, it is reasonable to speculate that the reduction in adiponectin may play a role in promoting the development of NAFLD. In addition, increased expression of NF- $\mathrm{kB}$ has been demonstrated in psoriasis [129]. The increase in ROS cause Th1 and Th17 cells and keratinocytes to activate the MAPK, NF- $\mathrm{kB}$ and JAK-STAT pathways [130, 131], thereby forming a selfamplification cycle that ultimately leads to excessive keratinocyte proliferation, vascular proliferation and inflammatory infiltration, which is also characteristic of psoriasis [132].

\section{Psoriatic arthritis}

Psoriatic arthritis (PsA) and plasma adiponectin levels are negatively correlated [133]. A previous study found that the adiponectin level was significantly higher in PsA patients than in psoriasis patients without arthritis [69]. However, a study of patients with psoriasis with or without PsA found that adiponectin levels were not significantly different [70]. It is possible that most psoriasis studies do not appropriately control for parameters, such as the presence of PsA, which may contribute to the inconsistency of the results if the groups are not properly adjusted [73]. The effect of lifestyle has also been studied, and it was found that alcohol consumption obviously affects the negative correlation between adiponectin and PsA occurrence [133].

\section{Mental disorders}

Psoriasis increases the risk of mental disorders, including depression, anxiety and suicide [134]. In addition to the psychological stress caused by psoriasis, it has been reported that inflammatory cytokines are related to mood disorders, including elevated levels of cytokines, including TNF-a, IL-6 and IL-1 [135, 136]. Anti-depressants reduce the central nervous system's inflammatory response and the levels of inflammatory cytokines, such as FAE $[135,137]$. This not only improves the psoriasis and adiponectin levels but also efficiently reduces depression symptoms [107]. It can be speculated that the increase in pro-inflammatory cytokines caused by the decrease in adiponectin levels in patients with psoriasis may be one of the causes of depression.

\section{Adiponectin and anti-psoriasis treatments}

In terms of treatment, secukinumab and etanercept have no relevant effect on adiponectin levels and they do not change the adiponectin level [70]. This may highlight that adiponectin levels are not closely related to PASI, a result consistent with other local and/or systemic treatment studies, except for analyses of secukinumab or 
other anti-IL-17 inhibitors [138, 139]. Patients using anti-inflammatory drugs or phototherapy may also have increased adiponectin levels [50, 140]. After mildly affected patients with no evidence of psoriatic arthritis received systemic methotrexate treatment, the PASI score was significantly reduced, but this treatment did not affect the serum adiponectin level [90]. During TNF- $\alpha$ treatment, an increase in adiponectin levels can also be observed [141]. Xue Li et al. found that hesperidin (Hes) can significantly improve psoriasis-like skin damage in mice and inhibit the proliferation of human immortalized keratinocytes $(\mathrm{HaCaT})$ by inhibiting the activation of the IRS-1/ERK1/2 signalling pathway. After Hes administration, adiponectin levels in mice were significantly upregulated, and PASI scores were remarkably reduced. The secretion of pro-inflammatory factors in skin lesions, epidermal hyperproliferation and differentiation, and epidermal thickness were also reduced [142]. In addition, the level of IL-17A decreased significantly and the level of adiponectin increased significantly after treatment with $\mathrm{Cal} / \mathrm{BD}$ aerosol foam. It is worth noting that there was a significant correlation between the improvement in PASI and the level of IL-17A [143]. Therefore, future research should examine the relationship between adiponectin and PASI and determine whether psoriasis can be treated by increasing adiponectin levels.

\section{Study strength and limitations}

This review comprehensively summarizes the possible role of adiponectin as an immunomodulator and the correlation between adiponectin levels and various clinical parameters, emphasizing that adiponectin is likely to become a new target for the treatment of psoriasis.

\section{Conclusions}

There is a complex relationship between psoriasis and fat. Studies on adipokines, particularly adiponectin, and their cytokine-related mechanisms are still insufficient, and information is lacking on whether these cytokines or their profiles can serve as biomarkers for psoriasis. Nevertheless, the importance of adiponectin in psoriasis is still of concern. With increasing research, the relationship between adiponectin and various systems of the body is becoming clearer, and changes in the expression of adiponectin can provide some guidance for patients with psoriasis regarding treatment. In the past, researchers have been more inclined to discuss systemic adiponectin, and the expression of local adiponectin in psoriasis may be more worthy of attention in the future. At the same time, it is also surprising that adiponectin may play a role as a lipid carrier, which provides a new direction for research. Currently, PASI is the gold standard for assessing the severity of psoriasis and its affected body regions, and the relationship between adiponectin and PASI should therefore be further clarified. In the evaluation of treatment, patient weight must be considered because there is a correlation between psoriasis and different comorbidities for which weight evaluation is valuable. The use of prior medications and the length of observation must also be considered, which may affect our judgement about the relationship between adiponectin and the course of psoriasis and even the evaluation of treatment efficacy. Furthermore, emphasis should also be placed on environmental and social factors involved in the disease, rather than focusing only on genetic and immune pathways. From a holistic perspective, a combination of biotherapy and measures to improve lifestyle can effectively alleviate the metabolic status of patients with psoriasis, including altering their adiponectin levels, which is indispensable for ameliorating the functional disorders of various systems in patients with psoriasis.

\begin{abstract}
Abbreviations
AMPK: Adenosine monophosphate protein kinase; p38 MAPK: p38 mitogenactivated protein kinase; PPARa: Peroxisome proliferator-activated receptor alpha; NF-kB: Nuclear factor KB; IL: Interleukin; TNF: Tumor necrosis factor; IFN: Interferon; SR: Sedimentation rate; CRP: C-reactive protein; SGs: Sebaceous glands; PASI: Psoriasis area and severity index; Hes: Hesperidin; HaCaT: Human immortalized keratinocytes; DIO: Dietinduced obesity; HFD: High-fat diet; BMI: Body mass index; LDL: Low density lipoprotein; VSMCs: Vascular smooth muscle cells; FoxO 1: Forkhead box O1; PVAT: Perivascular adipose tissue; FAE: Fumaric acid ester;

CVD: Cardiovascular disease; T2D: Type 2 Diabetes; NAFLD: Non-alcoholic fatty liver disease; PSA: Psoriatic arthritis; NO: Nitric oxide; SWAT: subcutaneous White adipose tissue; CTRP: C1q/TNF related protein; ROS: Reactive oxygen species
\end{abstract}

Acknowledgements

Not applicable.

Authors' contributions

RB and SF wrote the manuscript. AP edited the manuscript. RW and PZ revised the manuscript. The authors read and approved the final manuscript.

Funding

Not applicable.

Availability of data and materials

Not applicable.

\section{Declarations}

Ethics approval and consent to participate Not applicable.

Consent for publication

Not applicable.

Competing interests

The authors declare that they have no competing interests.

Author details

'Department of Dermatology, The Second Xiangya Hospital, Central South University, Changsha 410011, Hunan, China. 'Division of Plastic Surgery, Department of Surgery, Brigham and Women's Hospital and Harvard Medical School, 75 Francis St., Boston, MA 02115, USA. 
Received: 11 May 2021 Accepted: 20 July 2021

Published online: 09 August 2021

\section{References}

1. Nestle FO, Kaplan DH, Barker J. Psoriasis. N Engl J Med. 2009;361(5):496-509. https://doi.org/10.1056/NEJMra0804595.

2. Lowes MA, Russell CB, Martin DA, Towne JE, Krueger JG. The IL-23/T17 pathogenic axis in psoriasis is amplified by keratinocyte responses. Trends Immunol. 2013;34(4):174-81.

3. Raychaudhuri SK, Maverakis E, Raychaudhuri SP. Diagnosis and classification of psoriasis. Autoimmun Rev. 2014;13(4-5):490-5. https://doi.org/10.1016/j.a utrev.2014.01.008.

4. Rendon A, Schäkel K. Psoriasis Pathogenesis and Treatment. Int J Mol Sci. 2019;20(6):1475

5. Langley RG, Krueger GG, Griffiths CE. Psoriasis: epidemiology, clinical features, and quality of life. Ann Rheum Dis. 2005;64(Suppl 2):ii18-23 discussion ii24-5.

6. Armstrong AW, Read C. Pathophysiology, clinical presentation, and treatment of psoriasis: a review. JAMA. 2020;323(19):1945-60.

7. Parisi R, Iskandar IYK, Kontopantelis E, Augustin M, Griffiths CEM, Ashcroft DM. National, regional, and worldwide epidemiology of psoriasis: systematic analysis and modelling study. BMJ. 2020;369:m1590.

8. Chandran V, Raychaudhuri SP. Geoepidemiology and environmental factors of psoriasis and psoriatic arthritis. J Autoimmun. 2010;34(3):J314-21. https:// doi.org/10.1016/j.jaut.2009.12.001.

9. Ding X, Wang T, Shen Y, Wang X, Zhou C, Tian S, et al. Prevalence of psoriasis in China: a population-based study in six cities. Eur J Dermatol. 2012;22(5):663-7. https://doi.org/10.1684/ejd.2012.1802.

10. Bell LM, Sedlack R, Beard CM, Perry HO, Michet CJ, Kurland LT. Incidence of psoriasis in Rochester, Minn, 1980-1983. Arch Dermatol. 1991;127(8):1184-7. https://doi.org/10.1001/archderm.1991.01680070084010.

11. Jacob C, Meier F, Neidhardt K, Jugl SM, Walker J, Braun S, et al. Epidemiology and costs of psoriasis in Germany - a retrospective claims data analysis. Value Health. 2016;19(7):A566.

12. Egeberg A, Skov L, Gislason GH, Thyssen JP, Mallbris L. Incidence and prevalence of psoriasis in Denmark. Acta Derm Venereol. 2017;97(7):808-12. https://doi.org/10.2340/00015555-2672.

13. Springate DA, Parisi R, Kontopantelis E, Reeves D, Griffiths CE, Ashcroft DM. Incidence, prevalence and mortality of patients with psoriasis: a U.K. population-based cohort study. Br J Dermatol. 2017;176(3):650-8. https://doi. org/10.1111/bjd.15021.

14. Kubanova A, Kubanov A, Melekhina L, Bogdanova EV. The assessment of the incidence of skin disorders in Russian Federation in 2003-2016. Vestnik dermatologii i venerologii. 2017;93(6):22-33.

15. Schonmann Y, Ashcroft DM, Iskandar IYK, Parisi R, Sde-Or S, Comaneshter D, et al. Incidence and prevalence of psoriasis in Israel between 2011 and 2017. J Eur Acad Dermatol Venereol. 2019;33(11):2075-81. https://doi.org/1 $0.1111 / j d v .15762$.

16. Liang Y, Sarkar MK, Tsoi LC, Gudjonsson JE. Psoriasis: a mixed autoimmune and autoinflammatory disease. Curr Opin Immunol. 2017;49:1-8.

17. Lowes MA, Suarez-Farinas M, Krueger JG. Immunology of psoriasis. Annu Rev Immunol. 2014;32:227-55.

18. Yiu ZZN, Parisi R, Lunt M, Warren RB, Griffiths CEM, Langan SM, et al. Risk of hospitalisation and death due to infection in people with psoriasis: a population-based cohort study using the clinical practice research datalink. Br J Dermatol. 2021;184(1):178-86.

19. Amanat M, Salehi M, Rezaei N. Neurological and psychiatric disorders in psoriasis. Rev Neurosci. 2018;29(7):805-13.

20. Gisondi P, Barba E, Girolomoni G. Non-alcoholic fatty liver disease fibrosis score in patients with psoriasis. J Eur Acad Dermatol Venereol. 2016;30(2): 282-7. https://doi.org/10.1111/jdv.13456.

21. Coelho M, Oliveira T, Fernandes R. Biochemistry of adipose tissue: an endocrine organ. Arch Med Sci. 2013;9(2):191-200. https://doi.org/10.5114/a oms.2013.33181

22. Hotamisligil GS, Shargill NS, Spiegelman BM. Adipose expression of tumor necrosis factor-alpha: direct role in obesity-linked insulin resistance. Science. 1993:259(5091):87-91. https://doi.org/10.1126/science.7678183.

23. Trayhurn P, Wood IS. Adipokines: inflammation and the pleiotropic role of white adipose tissue. Br J Nutr. 2004;92(3):347-55. https://doi.org/10.1079/ BJN20041213.
24. Polito R, Nigro E, Messina A, Monaco ML, Monda V, Scudiero O, et al. Adiponectin and orexin-a as a potential immunity link between adipose tissue and central nervous system. Front Physiol. 2018;9:982. https://doi. org/10.3389/fphys.2018.00982.

25. Wong GW, Wang J, Hug C, Tsao TS, Lodish HF. A family of Acrp30/ adiponectin structural and functional paralogs. Proc Natl Acad Sci U S A. 2004;101(28):10302-7.

26. Ye JJ, Bian X, Lim J, Medzhitov R. Adiponectin and related C1q/TNF-related proteins bind selectively to anionic phospholipids and sphingolipids. Proc Natl Acad Sci U S A. 2020;117(29):17381-8. https://doi.org/10.1073/pnas.1 922270117.

27. Yamauchi T, Kamon J, Ito Y, Tsuchida A, Yokomizo T, Kita S, et al. Cloning of adiponectin receptors that mediate antidiabetic metabolic effects. Nature. 2003;423(6941):762-9.

28. Fang $H$, Judd RL. Adiponectin regulation and function. Compr Physiol. 2018; 8(3):1031-63. https://doi.org/10.1002/cphy.c170046.

29. Wang X, Chen Q, Pu H, Wei Q, Duan M, Zhang C, et al. Adiponectin improves NF-kappaB-mediated inflammation and abates atherosclerosis progression in apolipoprotein E-deficient mice. Lipids Health Dis. 2016;15:33.

30. Schäffler A, Buechler C. CTRP family: linking immunity to metabolism. Trends Endocrinol Metab. 2012;23(4):194-204. https://doi.org/10.1016/j.tem.2011.12. 003.

31. Wong GW, Krawczyk SA, Kitidis-Mitrokostas C, Revett T, Gimeno R, Lodish HF. Molecular, biochemical and functional characterizations of C1q/TNF family members: adipose-tissue-selective expression patterns, regulation by PPAR-gamma agonist, cysteine-mediated oligomerizations, combinatorial associations and metabolic functions. Biochem J. 2008;416(2):161-77.

32. Berg AH, Combs TP, Scherer PE. ACRP30/adiponectin: an adipokine regulating glucose and lipid metabolism. Trends Endocrinol Metab. 2002; 13(2):84-9. https://doi.org/10.1016/S1043-2760(01)00524-0.

33. Zhu KJ, Shi G, Zhang C, Li M, Zhu CY, Fan YM. Adiponectin levels in patients with psoriasis: a meta-analysis. J Dermatol. 2013:40(6):438-42. https://doi. org/10.1111/1346-8138.12121.

34. Bulur I, Erdogan HK, Kocaturk E, Saracoglu ZN, Alatas O, Yildiz P, et al. The role of irisin in the relationship between psoriasis and insulin resistance. $G$ Ital Dermatol Venereol. 2018;153(4):477-82. https://doi.org/10.23736/S03920488.16.05413-4

35. Versini $M$, Jeandel PY, Rosenthal E, Shoenfeld $Y$. Obesity in autoimmune diseases: not a passive bystander. Autoimmun Rev. 2014;13(9):981-1000. https://doi.org/10.1016/j.autrev.2014.07.001.

36. Sterry W, Strober BE, Menter A. Obesity in psoriasis: the metabolic, clinical and therapeutic implications. Report of an interdisciplinary conference and review. Br J Dermatol. 2007;157(4):649-55. https://doi.org/10.1111/j.13 65-2133.2007.08068.x.

37. Wong Y, Nakamizo S, Tan KJ, Kabashima K. An update on the role of adipose tissues in psoriasis. Front Immunol. 2019;10:1507. https://doi.org/1 0.3389/fimmu.2019.01507.

38. Takahashi H, Honma M, Ishida-Yamamoto A, lizuka H. Adiponectin and leptin modulate cell proliferation and cytokine secretion of normal human keratinocytes and T lymphocytes. J Dermatol Sci. 2010;59(2):143-5. https:// doi.org/10.1016/j.jdermsci.2010.06.004

39. Bai F, Zheng W, An J, Dong Y, Wang J, Garstka MA, et al. Serum levels of adipokines and cytokines in psoriasis patients: a systematic review and meta-analysis. Oncotarget. 2018;9:1266-78.

40. Gerdes S, Osadtschy S, Rostami-Yazdi M, Buhles N, Weichenthal M, Mrowietz $U$. Leptin, adiponectin, visfatin and retinol-binding protein-4 - mediators of comorbidities in patients with psoriasis? Exp Dermatol. 2012;21(1):43-7. https://doi.org/10.1111/j.1600-0625.2011.01402.x.

41. Shibata S, Saeki H, Tada Y, Karakawa M, Komine M, Tamaki K. Serum high molecular weight adiponectin levels are decreased in psoriasis patients. J Dermatol Sci. 2009:55(1):62-3.

42. Cataldi C, Mari NL, Lozovoy MAB, Martins LMM, Reiche EMV, Maes M, et al. Proinflammatory and anti-inflammatory cytokine profiles in psoriasis: use as laboratory biomarkers and disease predictors. Inflamm Res. 2019:68(7):55767. https://doi.org/10.1007/s00011-019-01238-8.

43. Campanati A, Ganzetti G, Giuliodori K, Marra M, Bonfigli A, Testa R, et al. Serum levels of adipocytokines in psoriasis patients receiving tumor necrosis factor-alpha inhibitors: results of a retrospective analysis. Int J Dermatol. 2015;54(7):839-45. https://doi.org/10.1111/ijd.12706.

44. Ouchi N, Kihara S, Funahashi T, Nakamura T, Nishida M, Kumada M, et al. Reciprocal association of $\mathrm{C}$-reactive protein with adiponectin in blood 
stream and adipose tissue. Circulation. 2003;107(5):671-4. https://doi.org/1 0.1161/01.CIR.0000055188.83694.B3.

45. Fantuzzi G. Adiponectin and inflammation: consensus and controversy. J Allergy Clin Immunol. 2008;121(2):326-30. https://doi.org/10.1016/j.jaci.2 007.10.018.

46. Baran A, Flisiak I, Jaroszewicz J, Swiderska M. Effect of psoriasis activity on serum adiponectin and leptin levels. Postepy Dermatol Alergol. 2015;32(2): 101-6. https://doi.org/10.5114/pdia.2014.40960.

47. Ghoshal K, Chatterjee T, Chowdhury S, Sengupta S, Bhattacharyya M. Adiponectin genetic variant and expression coupled with lipid peroxidation reveal new signatures in diabetic dyslipidemia. Biochem Genet. 2021;59(3): 781-98. https://doi.org/10.1007/s10528-021-10030-5.

48. Lihn AS, Pedersen SB, Richelsen B. Adiponectin: action, regulation and association to insulin sensitivity. Obes Rev. 2005;6(1):13-21. https://doi.org/1 0.1111/j.1467-789X.2005.00159.X.

49. Gerdes S, Rostami-Yazdi M, Mrowietz U. Adipokines and psoriasis. Exp Dermatol. 2011;20(2):81-7. https://doi.org/10.1111/j.1600-0625.2010.01210.x.

50. Bavoso NC, Pinto JM, Soares MMS, Diniz MDS, Teixeira Junior AL. Psoriasis in obesity: comparison of serum levels of leptin and adiponectin in obese subjects - cases and controls. An Bras Dermatol. 2019;94(2):192-7. https:// doi.org/10.1590/abd1806-4841.20197716.

51. Shibata S, Tada Y, Hau C, Tatsuta A, Yamamoto M, Kamata M, et al. Adiponectin as an anti-inflammatory factor in the pathogenesis of psoriasis: induction of elevated serum adiponectin levels following therapy. Br J Dermatol. 2011;164(3):667-70. https://doi.org/10.1111/j.1365-2133.2010.1 0123.x.

52. Coimbra S, Oliveira H, Reis F, Belo L, Rocha S, Quintanilha A, et al. Circulating adipokine levels in Portuguese patients with psoriasis vulgaris according to body mass index, severity and therapy. J Eur Acad Dermatol Venereol. 2010;24(12):1386-94. https://doi.org/10.1111/j.1468-3083.2010.0364 7.x.

53. Fantuzzi G. Adipose tissue, adipokines, and inflammation. J Allergy Clin Immunol. 2005;115(5):911-9; quiz 920. https://doi.org/10.1016/j.jaci.2005.02. 023.

54. Takahashi H, Tsuji H, Takahashi I, Hashimoto Y, Ishida-Yamamoto A, lizuka H. Plasma adiponectin and leptin levels in Japanese patients with psoriasis. $\mathrm{Br}$ J Dermatol. 2008;159(5):1207-8. https://doi.org/10.1111/j.1365-2133.2008. 08823.x.

55. Mehta NN, Shin DB, Joshi AA, Dey AK, Armstrong AW, Duffin KC, et al. Effect of 2 psoriasis treatments on vascular inflammation and novel inflammatory cardiovascular biomarkers: a randomized placebo-controlled trial. Circ Cardiovasc Imaging. 2018;11(6):e007394. https://doi.org/10.1161/CIRCIMA GING.117.007394.

56. Campanati A, Orciani M, Consales V, Lazzarini R, Ganzetti G, Di Benedetto G, et al. Characterization and profiling of immunomodulatory genes in resident mesenchymal stem cells reflect the Th1-Th17/Th2 imbalance of psoriasis. Arch Dermatol Res. 2014:306(10):915-20.

57. Surendar J, Frohberger SJ, Karunakaran I, Schmitt V, Stamminger W, Neumann AL, et al. Adiponectin limits IFN-gamma and IL-17 producing CD4 T cells in obesity by restraining cell intrinsic glycolysis. Front Immunol. 2019; 10:2555.

58. Shibata S, Tada Y, Hau CS, Mitsui A, Kamata M, Asano Y, et al. Adiponectin regulates psoriasiform skin inflammation by suppressing IL-17 production from gammadelta-T cells. Nat Commun. 2015;6(1):7687. https://doi.org/10.1 038/ncomms8687.

59. Kim JW, Lee YS, Seol DJ, Cho IJ, Ku SK, Choi JS, et al. Anti-obesity and fatty liver-preventing activities of Lonicera caerulea in high-fat diet-fed mice. Int J Mol Med. 2018:42(6):3047-64. https://doi.org/10.3892/ijmm.2018.3879.

60. Kim J, Krueger JG. The immunopathogenesis of psoriasis. Dermatol Clin. 2015;33(1):13-23. https://doi.org/10.1016/j.det.2014.09.002

61. Chen D, Pacal M, Wenzel P, Knoepfler PS, Leone G, Bremner R. Division and apoptosis of E2f-deficient retinal progenitors. Nature. 2009;462(7275):925-9.

62. Singh RK, Dagnino L. $\mathrm{CDH} 1$ regulates E2F1 degradation in response to differentiation signals in keratinocytes. Oncotarget. 2017;8(3):4977-93. https://doi.org/10.18632/oncotarget.13636.

63. Lee JH, Moon JH, Lee YJ, Park SY. SIRT1, a class III histone deacetylase, regulates LPS-induced inflammation in human keratinocytes and mediates the antiinflammatory effects of Hinokitiol. J Invest Dermatol. 2017;137(6):1257-66.

64. Saunders N, Dahler A, Jones S, Smith R, Jetten A. Interferon-gamma as a regulator of squamous differentiation. J Dermatol Sci. 1996;13(2):98-106. https://doi.org/10.1016/S0923-1811(96)00535-X.
65. Jin T, Kim MJ, Heo WI, Park KY, Choi SY, Lee MK, et al. Adiponectin corrects premature cellular senescence and normalizes antimicrobial peptide levels in senescent keratinocytes. Biochem Biophys Res Commun. 2016:477(4):67884. https://doi.org/10.1016/j.bbrc.2016.06.119.

66. Zhang $M$, Zhang $X$. The role of PI3K/AKT/FOXO signaling in psoriasis. Arch Dermatol Res. 2019;311(2):83-91. https://doi.org/10.1007/s00403-018-1879-8.

67. Singh $\mathrm{V}$, Ubaid $\mathrm{S}$. Role of silent information regulator 1 (SIRT1) in regulating oxidative stress and inflammation. Inflammation. 2020;43(5):1589-98.

68. Kovacs D, Lovaszi M, Poliska S, Olah A, Biro T, Veres I, et al. Sebocytes differentially express and secrete adipokines. Exp Dermatol. 2016;25(3):1949. https://doi.org/10.1111/exd.12879.

69. Eder L, Jayakar J, Pollock R, Pellett F, Thavaneswaran A, Chandran V, et al. Serum adipokines in patients with psoriatic arthritis and psoriasis alone and their correlation with disease activity. Ann Rheum Dis. 2013;72(12):1956-61.

70. Gerdes S, Pinter A, Biermann M, Papavassilis C, Reinhardt M. Adiponectin levels in a large pooled plaque psoriasis study population. J Dermatolog Treat. 2020;31(5):531-4.

71. Chan WSA, Liew CF, Theng CTS, Oon HH. Serum adiponectin levels and their association with Cardiometabolic risk factors in patients with psoriasis. Cureus. 2020;12(5):e8128.

72. Kruglikov IL, Scherer PE, Wollina U. Are dermal adipocytes involved in psoriasis? Exp Dermatol. 2016;25(10):812-3. https://doi.org/10.1111/exd.12 996.

73. Kruglikov IL, Wollina U. Local effects of adipose tissue in psoriasis and psoriatic arthritis. Psoriasis (Auckl). 2017;7:17-25. https://doi.org/10.2147/PTT. S122959.

74. Brembilla NC, Boehncke WH. Dermal adipocytes' claim for fame in psoriasis. Exp Dermatol. 2017;26(5):392-3. https://doi.org/10.1111/exd.13074.

75. Leung DY, Walsh P, Giorno R, Norris DA. A potential role for superantigens in the pathogenesis of psoriasis. J Invest Dermatol. 1993;100(3):225-8. https://doi.org/10.1111/1523-1747.ep12468941.

76. Zhang LJ, Guerrero-Juarez CF, Hata T, Bapat SP, Ramos R, Plikus MV, et al. Innate immunity. Dermal adipocytes protect against invasive Staphylococcus aureus skin infection. Science. 2015;347(6217):67-71.

77. Clausen ML, Slotved HC, Krogfelt KA, Andersen PS, Agner T. In vivo expression of antimicrobial peptides in atopic dermatitis. Exp Dermatol. 2016;25(1):3-9. https://doi.org/10.1111/exd.12831.

78. Dattola A, Altobelli S, Marsico S, Plastina D, Nistico SP, Cavallo A, et al. Hypodermal adipose tissue Sonoelastography for monitoring treatment response in patients with plaque psoriasis. Photomed Laser Surg. 2017;35(9): 484-91. https://doi.org/10.1089/pho.2016.4261.

79. Kruglikov IL, Wollina U. The role of subcutaneous adipose tissue in psoriasis. J Biol Regul Homeost Agents. 2018;32(1):159-61.

80. Armstrong AW, Harskamp CT, Armstrong EJ. The association between psoriasis and obesity: a systematic review and meta-analysis of observational studies. Nutr Diabetes. 2012;2:e54.

81. Goolam Mahyoodeen N. N.J. Crowther, L. Pillay, T. Snyman, M. Toman, S Daya, et al., relationship of visceral fat and Adipokines with Cardiometabolic diseases in psoriasis. Acta Derm Venereol. 2019;99(13):1218-23. https://doi. org/10.2340/00015555-3327.

82. Rodriguez-Cerdeira C, Cordeiro-Rodriquez M, Carnero-Gregorio M, LopezBarcenas A, Martinez-Herrera E, Fabbrocini G, et al. Biomarkers of inflammation in obesity-psoriatic patients. Mediat Inflamm. 2019;2019:7353420.

83. Kang YE, Kim JM, Joung KH, Lee JH, You BR, Choi MJ, et al. The roles of Adipokines, Proinflammatory cytokines, and adipose tissue macrophages in obesity-associated insulin resistance in modest obesity and early metabolic dysfunction. PLoS One. 2016;11(4):e0154003. https://doi.org/10.1371/journal. pone. 0154003

84. Ouchi N, Parker JL, Lugus JJ, Walsh K. Adipokines in inflammation and metabolic disease. Nat Rev Immunol. 2011;11(2):85-97. https://doi.org/10.1 038/nri2921.

85. Tollefson MM, Van Houten HK, Asante D, Yao X, Maradit Kremers H. Association of Psoriasis with Comorbidity Development in children with psoriasis. JAMA Dermatol. 2018;154(3):286-92. https://doi.org/10.1001/jama dermatol.2017.5417.

86. Takahashi H, lizuka H. Psoriasis and metabolic syndrome. J Dermatol. 2012; 39(3):212-8. https://doi.org/10.1111/j.1346-8138.2011.01408.X.

87. Son M, Oh S, Lee HS, Chung DM, Jang JT, Jeon YJ, et al. Ecklonia cava extract attenuates endothelial cell dysfunction by modulation of inflammation and brown adipocyte function in perivascular fat tissue. Nutrients. 2019;11(11):2795. 
88. Oh YJ, Lim HK, Choi JH, Lee JW, Kim NI. Serum leptin and adiponectin levels in Korean patients with psoriasis. J Korean Med Sci. 2014;29(5):729-34. https://doi.org/10.3346/jkms.2014.29.5.729.

89. Warnecke C, Manousaridis I, Herr R, Terris DD, Goebeler M, Goerdt S, et al. Cardiovascular and metabolic risk profile in German patients with moderate and severe psoriasis: a case control study. Eur J Dermatol. 2011;21(5):761-70. https://doi.org/10.1684/ejd.2011.1467.

90. Coban M, Tasli L, Turgut S, Ozkan S, Tunc Ata M, Akin F. Association of Adipokines, insulin resistance, hypertension and dyslipidemia in patients with psoriasis vulgaris. Ann Dermatol. 2016;28(1):74-9.

91. Toussirot E, Aubin F, Desmarets M, Wendling D, Augé B, Gillard J, et al. Visceral adiposity in patients with psoriatic arthritis and psoriasis alone and its relationship with metabolic and cardiovascular risk. Rheumatology (Oxford). 2020;60(6):2816-25.

92. Bremmer S, Van Voorhees AS, Hsu S, Korman NJ, Lebwohl MG, Young M, et al. Obesity and psoriasis: from the medical Board of the National Psoriasis Foundation. J Am Acad Dermatol. 2010;63(6):1058-69. https://doi.org/10.101 6/j.jaad.2009.09.053.

93. Peluso I, Palmery M. The relationship between body weight and inflammation: lesson from anti-TNF-a antibody therapy. Hum Immunol. 2016;77(1):47-53.

94. Florin V, Cottencin AC, Delaporte E, Staumont-Sallé D. Body weight increment in patients treated with infliximab for plaque psoriasis. J Eur Acad Dermatol Venereol. 2013;27(2):e186-90. https://doi.org/10.1111/j.1468-3083.2 012.04571.x

95. Shlyankevich J, Mehta NN, Krueger JG, Strober B, Gudjonsson JE, Qureshi AA, et al. Accumulating evidence for the association and shared pathogenic mechanisms between psoriasis and cardiovascular-related comorbidities. Am J Med. 2014;127(12):1148-53. https://doi.org/10.1016/j.amjmed.2014.08. 008.

96. Manolis AA, Manolis TA, Melita H, Manolis AS. Psoriasis and cardiovascular disease: the elusive link. Int Rev Immunol. 2019;38(1):33-54. https://doi.org/1 0.1080/08830185.2018.1539084

97. Li RC, Krishnamoorthy P, DerOhannessian S, Doveikis J, Wilcox M, Thomas P, et al. Psoriasis is associated with decreased plasma adiponectin levels independently of cardiometabolic risk factors. Clin Exp Dermatol. 2014;39(1): 19-24. https://doi.org/10.1111/ced.12250.

98. Szmitko PE, Teoh H, Stewart DJ, Verma S. Adiponectin and cardiovascular disease: state of the art? Am J Physiol Heart Circ Physiol. 2007;292(4):H165563.

99. Darios ES, Winner BM, Charvat T, Krasinksi A, Punna S, Watts SW. The adipokine chemerin amplifies electrical field-stimulated contraction in the isolated rat superior mesenteric artery. Am J Physiol Heart Circ Physiol. 2016; 311(2):H498-507. https://doi.org/10.1152/ajpheart.00998.2015.

100. Lu CL, Liao MT, Hou YC, Fang YW, Zheng CM, Liu WC, et al. Sirtuin-1 and its relevance in vascular calcification. Int J Mol Sci. 2020;21(5):1593.

101. Qiao L, Shao J. SIRT1 regulates adiponectin gene expression through Foxo1C/enhancer-binding protein alpha transcriptional complex. J Biol Chem. 2006;281(52):39915-24. https://doi.org/10.1074/jbc.M607215200.

102. Ouchi N, Kihara S, Arita Y, Maeda K, Kuriyama H, Okamoto Y, et al. Novel modulator for endothelial adhesion molecules: adipocyte-derived plasma protein adiponectin. Circulation. 1999;100(25):2473-6. https://doi.org/10.11 61/01.CIR.100.25.2473

103. Almabrouk TA, Ewart MA, Salt IP, Kennedy S. Perivascular fat, AMP-activated protein kinase and vascular diseases. Br J Pharmacol. 2014;171(3):595-617. https://doi.org/10.1111/bph.12479.

104. Cavusoglu E, Ruwende C, Chopra V, Yanamadala S, Eng C, Clark LT, et al. Adiponectin is an independent predictor of all-cause mortality, cardiac mortality, and myocardial infarction in patients presenting with chest pain. Eur Heart J. 2006;27(19):2300-9. https://doi.org/10.1093/eurheartj/ehl153.

105. Dekker JM, Funahashi T, Nijpels G, Pilz S, Stehouwer CD, Snijder MB, et al. Prognostic value of adiponectin for cardiovascular disease and mortality. J Clin Endocrinol Metab. 2008;93(4):1489-96. https://doi.org/10.1210/jc.2007-1436.

106. Wu JJ, Poon KY, Channual JC, Shen AY. Association between tumor necrosis factor inhibitor therapy and myocardial infarction risk in patients with psoriasis. Arch Dermatol. 2012;148(11):1244-50. https://doi.org/10.1001/a rchdermatol.2012.2502.

107. Schmieder A, Poppe M, Hametner C, Meyer-Schraml H, Schaarschmidt ML, Findeisen $P$, et al. Impact of fumaric acid esters on cardiovascular risk factors and depression in psoriasis: a prospective pilot study. Arch Dermatol Res. 2015;307(5):413-24.
108. Boehncke S, Salgo R, Garbaraviciene J, Beschmann H, Hardt K, Diehl S, et al. Effective continuous systemic therapy of severe plaque-type psoriasis is accompanied by amelioration of biomarkers of cardiovascular risk: results of a prospective longitudinal observational study. J Eur Acad Dermatol Venereol. 2011;25(10):1187-93.

109. Vezza T, Rodriguez-Nogales A, Algieri F, Garrido-Mesa J, Romero M, Sanchez $M$, et al. The metabolic and vascular protective effects of olive (Olea europaea L.) leaf extract in diet-induced obesity in mice are related to the amelioration of gut microbiota dysbiosis and to its immunomodulatory properties. Pharmacol Res. 2019;150:104487.

110. Woodward L, Akoumianakis I, Antoniades C. Unravelling the adiponectin paradox: novel roles of adiponectin in the regulation of cardiovascular disease. Br J Pharmacol. 2017;174(22):4007-20.

111. Ruscica M, Baragetti A, Catapano AL, Norata GD. Translating the biology of adipokines in atherosclerosis and cardiovascular diseases: gaps and open questions. Nutr Metab Cardiovasc Dis. 2017;27(5):379-95. https://doi.org/10.1 016/j.numecd.2016.12.005.

112. Katsiki N, Mantzoros C, Mikhailidis DP. Adiponectin, lipids and atherosclerosis. Curr Opin Lipidol. 2017;28(4):347-54. https://doi.org/10.1097/ MOL.0000000000000431

113. Kaur S, Kingo K, Zilmer M. Psoriasis and cardiovascular risk-do promising new biomarkers have clinical impact? Mediat Inflamm. 2017;2017:7279818.

114. Xu X, Su L, Gao Y, Ding Y. The prevalence of nonalcoholic fatty liver disease and related metabolic comorbidities was associated with age at onset of moderate to severe plaque psoriasis: a cross-sectional study. PLoS One. 2017;12(1):e0169952. https://doi.org/10.1371/journal.pone.0169952.

115. Panera N, Della Corte C, Crudele A, Stronati L, Nobili V, Alisi A. Recent advances in understanding the role of adipocytokines during non-alcoholic fatty liver disease pathogenesis and their link with hepatokines. Exp Rev Gastroenterol Hepatol. 2016;10(3):393-403. https://doi.org/10.1586/174 74124.2016.1110485.

116. Wolk K, Sabat R. Adipokines in psoriasis: An important link between skin inflammation and metabolic alterations. Rev Endocr Metab Disord. 2016; 17(3):305-17. https://doi.org/10.1007/s11154-016-9381-0.

117. Hennige AM, Staiger H, Wicke C, Machicao F, Fritsche A, Häring HU, et al. Fetuin-a induces cytokine expression and suppresses adiponectin production. PLoS One. 2008;3(3):e1765. https://doi.org/10.1371/journal.pone. 0001765.

118. Rajappa M, Rathika S, Munisamy M, Chandrashekar L, Thappa DM. Effect of treatment with methotrexate and coal tar on adipokine levels and indices of insulin resistance and sensitivity in patients with psoriasis vulgaris. J Eur Acad Dermatol Venereol. 2015;29(1):69-76.

119. Kong Y, Zhang S, Wu R, Su X, Peng D, Zhao M, et al. New insights into different adipokines in linking the pathophysiology of obesity and psoriasis. Lipids Health Dis. 2019;18(1):171. https://doi.org/10.1186/s12944-019-1115-3.

120. Mantzoros CS, Li T, Manson JE, Meigs JB, Hu FB. Circulating adiponectin levels are associated with better glycemic control, more favorable lipid profile, and reduced inflammation in women with type 2 diabetes. J Clin Endocrinol Metab. 2005;90(8):4542-8. https://doi.org/10.1210/jc.2005-0372.

121. Arnaboldi L, Corsini A. Could changes in adiponectin drive the effect of statins on the risk of new-onset diabetes? The case of pitavastatin. Atheroscler Suppl. 2015;16:1-27. https://doi.org/10.1016/S1567-5688(14 )70002-9.

122. Thakker D, Nair S, Pagada A, Jamdade V, Malik A. Statin use and the risk of developing diabetes: a network meta-analysis. Pharmacoepidemiol Drug Saf. 2016;25(10):1131-49.

123. van der Voort EA, Koehler EM, Dowlatshahi EA, Hofman A, Stricker BH, Janssen $\mathrm{HL}$, et al. Psoriasis is independently associated with nonalcoholic fatty liver disease in patients 55 years old or older: results from a population-based study. J Am Acad Dermatol. 2014;70(3):517-24. https://doi. org/10.1016/j.jaad.2013.10.044.

124. Miele L, Vallone S, Cefalo C, La Torre G, Di Stasi C, Vecchio FM, et al. Prevalence, characteristics and severity of non-alcoholic fatty liver disease in patients with chronic plaque psoriasis. J Hepatol. 2009;51(4):778-86. https:// doi.org/10.1016/j.jhep.2009.06.008.

125. Stojsavljevic S, Gomercic Palcic M, Virovic Jukic L, Smircic Durnjak L, Duvnjak M. Adipokines and proinflammatory cytokines, the key mediators in the pathogenesis of nonalcoholic fatty liver disease. World J Gastroenterol. 2014;20(48):18070-91. https://doi.org/10.3748/wjg.v20.i48.18070.

126. Roberts KK, Cochet AE, Lamb PB, Brown PJ, Battafarano DF, Brunt EM, et al. The prevalence of NAFLD and NASH among patients with psoriasis in a 
tertiary care dermatology and rheumatology clinic. Aliment Pharmacol Ther. 2015;41(3):293-300. https://doi.org/10.1111/apt.13042.

127. Prussick RB, Miele L. Nonalcoholic fatty liver disease in patients with psoriasis: a consequence of systemic inflammatory burden? Br J Dermatol. 2018;179(1):16-29. https://doi.org/10.1111/bjd.16239.

128. Dong Z, Zhuang Q, Ye X, Ning M, Wu S, Lu L, et al. Adiponectin inhibits NLRP3 Inflammasome activation in nonalcoholic steatohepatitis via AMPKJNK/ErK1/2-NFkB/ROS signaling pathways. Front Med (Lausanne). 2020;7: 546445. https://doi.org/10.3389/fmed.2020.546445.

129. Lin $X$, Huang T. Oxidative stress in psoriasis and potential therapeutic use of antioxidants. Free Radic Res. 2016;50(6):585-95. https://doi.org/10.3109/1071 5762.2016.1162301.

130. Becatti M, Barygina V, Mannucci A, Emmi G, Prisco D, Lotti T, et al. Sirt1 protects against oxidative stress-induced apoptosis in fibroblasts from psoriatic patients: A new insight into the pathogenetic mechanisms of psoriasis. Int J Mol Sci. 2018;19(6):1572.

131. Lei Y, Wang K, Deng L, Chen Y, Nice EC, Huang C. Redox regulation of inflammation: old elements, a new story. Med Res Rev. 2015;35(2):306-40. https://doi.org/10.1002/med.21330.

132. Xu F, Xu J, Xiong X, Deng Y. Salidroside inhibits MAPK, NF-KB, and STAT3 pathways in psoriasis-associated oxidative stress via SIRT1 activation. Redox Rep. 2019;24(1):70-4. https://doi.org/10.1080/13510002.2019.1658377.

133. Johnson CM, Fitch K, Merola JF, Han J, Qureshi AA, Li WQ. Plasma levels of tumour necrosis factor-alpha and adiponectin can differentiate patients with psoriatic arthritis from those with psoriasis. Br J Dermatol. 2019;181(2): 379-80. https://doi.org/10.1111/bjd.17700.

134. Kurd SK, Troxel AB, Crits-Christoph P, Gelfand JM. The risk of depression, anxiety, and suicidality in patients with psoriasis: a population-based cohort study. Arch Dermatol. 2010;146(8):891-5. https://doi.org/10.1001/archderma tol.2010.186.

135. Hashmi AM, Butt Z, Umair M. Is depression an inflammatory condition? A review of available evidence. J Pak Med Assoc. 2013;63(7):899-906.

136. Das R, Emon MPZ, Shahriar M, Nahar Z, Islam SMA, Bhuiyan MA, et al. Higher levels of serum IL-1 $\beta$ and TNF- $\alpha$ are associated with an increased probability of major depressive disorder. Psychiatry Res. 2021;295:113568. https://doi.org/10.1016/j.psychres.2020.113568.

137. Wilms H, Sievers J, Rickert U, Rostami-Yazdi M, Mrowietz U, Lucius R Dimethylfumarate inhibits microglial and astrocytic inflammation by suppressing the synthesis of nitric oxide, IL-1 beta, TNF-alpha and IL-6 in an in-vitro model of brain inflammation. J Neuroinflammation. 2010;7(1):30. https://doi.org/10.1186/1742-2094-7-30.

138. Kyriakou A, Patsatsi A, Sotiriadis D, Goulis DG. Effects of treatment for psoriasis on circulating levels of leptin, adiponectin and resistin: a systematic review and meta-analysis. Br J Dermatol. 2018;179(2):273-81.

139. Baran A, Flisiak I, Jaroszewicz J, Świderska M. Serum adiponectin and leptin levels in psoriatic patients according to topical treatment. J Dermatolog Treat. 2015;26(2):134-8. https://doi.org/10.3109/09546634.2014.915917.

140. Coimbra S, Oliveira H, Reis F, Belo L, Rocha S, Quintanilha A, et al. Psoriasis therapy and cardiovascular risk factors: a 12-week follow-up study. Am J Clin Dermatol. 2010;11(6):423-32. https://doi.org/10.2165/11319310000000000-00000

141. Corrado A, Colia R, Rotondo C, Sanpaolo E, Cantatore FP. Changes in serum adipokines profile and insulin resistance in patients with rheumatoid arthritis treated with anti-TNF-a. Curr Med Res Opin. 2019;35(12):2197-205.

142. Li X, Xie X, Zhang L, Meng Y, Li N, Wang M, et al. Hesperidin inhibits keratinocyte proliferation and imiquimod-induced psoriasis-like dermatitis via the IRS-1/ERK1/2 pathway. Life Sci. 2019;219:311-21.

143. Ropke M, Bulai Livideanu C, Kaldate R, Snel A, Paul C. Changes in interleukin-17A, macrophage-derived chemokine and adiponectin following treatment of psoriasis with calcipotriol plus betamethasone dipropionate aerosol foam: results from the PSO-ABLE study. Br J Dermatol. 2018;178(1): e33-4. https://doi.org/10.1111/bjd.15814.

\section{Publisher's Note}

Springer Nature remains neutral with regard to jurisdictional claims in published maps and institutional affiliations.

Ready to submit your research? Choose BMC and benefit from:

- fast, convenient online submission

- thorough peer review by experienced researchers in your field

- rapid publication on acceptance

- support for research data, including large and complex data types

- gold Open Access which fosters wider collaboration and increased citations

- maximum visibility for your research: over $100 \mathrm{M}$ website views per year

At BMC, research is always in progress.

Learn more biomedcentral.com/submissions 